\title{
Bcr/Abl P190 interaction with Spa-1, a GTPase activating protein for the small GTPase Rap1
}

\author{
SUN-JU YI ${ }^{1}$, HYUNG-TAEK LEE ${ }^{1,3}$, JOHN GROFFEN ${ }^{1,2}$ and NORA HEISTERKAMP ${ }^{1,2}$ \\ ${ }^{1}$ Section of Molecular Carcinogenesis, Division of Hematology/Oncology, Ms\#54, The Saban Research Institute of \\ Childrens Hospital Los Angeles, 4650 Sunset Boulevard, Los Angeles, CA 90027; ${ }^{2}$ Department of Pathology, \\ Keck School of Medicine, University of Southern California, Los Angeles, CA 90033, USA
}

Received May 22, 2008; Accepted July 2, 2008

DOI: 10.3892/ijmm_00000042

\begin{abstract}
The Bcr/Abl oncogene is responsible for the development of $\mathrm{Ph}$-chromosome positive acute lymphoblastic leukemia and chronic myelogenous leukemia in humans. Previous studies demonstrated that $\mathrm{Bcr} / \mathrm{Abl}$ expression is associated with elevated levels of activated Rap1, a small GTPase. Levels of activated Rap1 are determined by a balance between GTPase activating and G-nucleotide exchange factor activity. We show that Bcr/Abl forms a protein-protein complex with Spa-1, a GTPase activating protein for Rap1, both in COS- 1 cells as well as in primary lymphoblastic leukemia cells from a transgenic P190 BCR/ABL mouse model. The interaction between Spa-1 and P190 did not affect the tyrosine kinase activity of P190, nor did Spa-1 become phosphorylated on tyrosine as a result of the interaction. P190 and Spa-1 co-localized to peripheral actin structures in primary lymphoblasts and expression of Spa-1 in the leukemic lymphoblasts decreased the migration of these cells. The binding of Bcr/Abl to Spa-1 may cause aberrant subcellular location of Spa-1 and affect migration of these cells.
\end{abstract}

\section{Introduction}

$B C R$ was discovered as a gene that becomes aberrantly fused to the $A B L$ proto-oncogene during a specific chromosomal translocation $\mathrm{t}(9 ; 22)$ that generates the $\mathrm{Ph}$-chromosome. The resulting $\mathrm{Bcr} / \mathrm{Abl}$ fusion protein that is produced from the translocated chromosome causes chronic myelogenous leukemia (CML) and a subclass of Ph-positive acute lymphoblastic leukemia (ALL) $(1,2)$. The two main forms of Bcr/Abl called P190 and P210 differ in their Bcr moiety but share the

Correspondence to: Dr N. Heisterkamp, Division of Hematology/ Oncology, Ms\#54, Childrens Hospital Los Angeles, 4650 Sunset Blvd., Los Angeles, CA 90027, USA

E-mail: heisterk@hsc.usc.edu

Present address: ${ }^{3}$ HepaHope Inc., 152 Technology Dr, Irvine, CA 92618, USA

Key words: acute lymphoblastic leukemia, Ph-positive, oncogene, migration, small G-protein, subcellular location same Abl segment. P190 is mainly associated with Ph-positive ALL, whereas P210 is predominantly found in CML. The $\mathrm{Bcr} / \mathrm{Abl}$ proteins have deregulated tyrosine kinase activity. Currently, the tyrosine kinase inhibitor Imatinib/Gleevec is the standard treatment for CML, with long-term remission achieved for the majority of patients. However, patients with Ph-positive ALL do not obtain a durable remission with Imatinib alone, and the prognosis for patients with this type of leukemia remains poor $(3,4)$.

The signal transduction pathways perturbed by Bcr/Abl remain a focus of research. Small GTPases such as Ras, Rac and Rap are of special interest since they act as molecular switches and regulate numerous properties relevant to leukemic cells such as proliferation, differentiation, migration and adhesion.

The activation and deactivation cycle of Rap1 is regulated by guanine nucleotide exchange factors (GEFs) and GTPase activating proteins (GAPs). We previously showed that $\mathrm{Bcr}$ / Abl elevates GTP-Rap1 levels through tyrosine phosphorylation and activation of $\mathrm{C} 3 \mathrm{G}$, a key GEF for Rap (5). Using Ton.B cells transduced with a regulatable $\mathrm{Bcr} / \mathrm{Abl}$ construct Mizuchi et al (6) showed that Bcr/Abl induction resulted in Rap1 activation. Similarly, Jin et al (7), using the same system, demonstrated that Bcr/Abl induction causes Rap1 activation and further downstream effects. The exact mechanism by which Bcr/Abl induces Rap1 activation was not described.

The small GTPase Rap1 appears to be of general significance to leukemogenesis. Although it was originally isolated as a small GTPase that antagonizes Ras transformation, more recent investigations indicate that Rap1 regulates integrinmediated adhesion (8). A first report linking Rap1 to leukemia was one that showed that acute myeloid leukemia in some BXH-2 mice is caused by activation of a GEF for Rap1 (CALDAG-GEF1) by retroviral insertion (9). Ishida et al (10) generated a null mutant for Spa-1, a principal GAP for Rap1 in hematopoietic progenitors. Remarkably, Spa-1 knockouts develop a spectrum of myeloid disorders resembling chronic and blast crisis CML $(10,11)$. Recently, using bone marrow progenitor cells from wild-type and $\mathrm{Spa}-1^{-/}$mice transduced with a Bcr/Abl P210 retrovirus, Kometani et al (12) showed that Spa-1 is involved in regulating expansion or survival of $\mathrm{Bcr} / \mathrm{Abl}$ progenitors. Wang et al (13) also provided further evidence for the importance of regulation of GTP-Rap1 levels in hematopoietic cell types. They showed that Spa-1/ 
mice developed a lethal T-cell ALL when they were also transgenic for a farnesylated $\mathrm{C} 3 \mathrm{G}$ construct. Therefore, there is compelling evidence that non-regulated increases in the levels of activated Rap1 cause the development of leukemia in mice.

Since we found that $\mathrm{Bcr} / \mathrm{Abl}$ affects levels of activated Rap1 through C3G, and Spa-1 null mutants develop myeloproliferative disorders and frank leukemia associated with increased levels of GTP-Rap, we considered the possibility that activities of Bcr/Abl and Spa-1 are linked. Surprisingly, we found that $\mathrm{Bcr} / \mathrm{Abl}$ co-localizes with Spa-1 in primary transgenic $B C R / A B L$ P190 leukemic cells and forms a stable protein complex with it that is mediated through the Abl part.

\section{Materials and methods}

Constructs and antibodies. pCDE-Bcr/Abl p190, pCDE$\mathrm{Bcr} / \mathrm{Abl}$ p210 and pSG5-Abl have been described previously (14). We obtained the pCMV6-XL6-Spa-1 plasmid from Origene Technologies, Inc. (Rockville, MD). The Spa-1 insert was subcloned as a NotI x SspI fragment into pSK digested with NotI $x$ SmaI. For the experiments shown in Fig. 3, Spa-1 was subcloned into the pCCL-cppt-MNDU3 vector. For the experiments shown in Fig. 4, the insert of Spa-1/pSKII was removed as a 3.3-kb EcoRI fragment and subcloned into pCCL-c-MNDU3-PGK-EGFP digested with EcoRI. Anti-Bcr (N-20) and anti-Bcr (C-20) antibodies were purchased from Santa Cruz Biotechnology (Santa Cruz, CA). Anti-Spa-1 antibodies and anti-Rap1 antibodies were obtained from BD Biosciences (Franklin Lakes, NJ). Anti-c-Abl antibodies (Ab-3) for immunoprecipitation were purchased from Calbiochem (San Diego, CA) and anti-Abl (3F12) was a gift from Ravi Salgia (Department of Medicine, University of Chicago, Chicago, IL).

Cell culture, immunoprecipitation, determination of GTP-Rap1 levels. COS-1 cells were grown in DMEM supplemented with $10 \%$ FBS, penicillin $(100 \mathrm{U} / \mathrm{ml})$ and streptomycin $(100 \mu \mathrm{g} / \mathrm{ml})$, $1 \mathrm{mM}$ sodium pyruvate, and $2 \mathrm{mM}$ L-glutamine. Transfections were performed using Lipofectamine and PLUS according to the manufacturer's instruction (Invitrogen, Carlsbad, CA). After $48 \mathrm{~h}$, lysates were prepared in Triton-lysis buffer (50 mM Tris, pH 7.5, $150 \mathrm{mM} \mathrm{NaCl}, 1 \%$ Triton X-100, 5 mM EDTA, $50 \mathrm{mM} \mathrm{NaF}, 1 \mathrm{mM} \mathrm{Na} \mathrm{VO}_{4}, 1 \mathrm{mM}$ PMSF, $10 \mu \mathrm{g} / \mathrm{ml}$ aprotinin, $10 \mu \mathrm{g} / \mathrm{ml}$ leupeptin, $1 \mu \mathrm{g} / \mathrm{ml}$ pepstatin). Precleared cell lysates were incubated with antibodies for $2 \mathrm{~h}$ or overnight at $4^{\circ} \mathrm{C}$ followed by adding protein $\mathrm{G}$ or protein $\mathrm{A}$-conjugate agarose beads for $1 \mathrm{~h}$ at $4^{\circ} \mathrm{C}$. The PLC1 cell line has been previously described (15). Cells were isolated from the lymphomas of $B C R / A B L$ P190 transgenic mice $(16,17)$ and grown in McCoy's 5A modified medium (Invitrogen, Carlsbad, CA) supplemented with $15 \% \mathrm{FBS}$, penicillin $(100 \mathrm{U} / \mathrm{ml})$ and streptomycin $(100 \mu \mathrm{g} / \mathrm{ml}), 1 \mathrm{mM}$ sodium pyruvate, $2 \mathrm{mM}$ L-glutamine, freshly added $50 \mu \mathrm{M} ß$-mercaptoethanol and $10 \mathrm{ng} / \mathrm{ml}$ IL-3 on irradiated mouse embryonic fibroblasts. Lymphoma lysates were prepared in Triton lysis buffer $(25 \mathrm{mM}$ sodium phosphate, $\mathrm{pH} 7.5,5 \mathrm{mM}$ EDTA, $150 \mathrm{mM} \mathrm{NaCl}, 1 \%$ Triton $\mathrm{X}-100,50 \mathrm{mM} \mathrm{NaF}, 10 \mu \mathrm{g} / \mathrm{ml}$ aprotinin and leupeptin, $1 \mathrm{mM} \mathrm{Na}_{3} \mathrm{VO}_{4}$ and $1 \mathrm{mM}$ PMSF). The lysates $(1.5 \mathrm{mg}$ of protein) were precleared with protein A agarose beads (Invitrogen, Carlsbad, CA) before immunoprecipitation with antibodies. Nalm-6 cells obtained from the ATCC were grown in RPMI containing $10 \%$ FBS, penicillin $(100 \mathrm{U} / \mathrm{ml})$ and streptomycin $(100 \mu \mathrm{g} / \mathrm{ml}), 1 \mathrm{mM}$ sodium pyruvate, and $2 \mathrm{mM}$ L-glutamine. For measurement of active GTP-Rap1 levels, the GST-RalGDS-Rap binding domain was purified from E. coli (5) and GTP-Rap1 levels were measured as previously described (18).

Immunofluorescence microscopy. Cells were cultured for $48 \mathrm{~h}$ prior to fixation. For microscopy, cells were washed twice with PBS and fixed in 4\% paraformaldehyde (Electronic Scientific Co., Hatfield, PA) [15 min at room temperature (RT)], followed by permeabilization in $0.2 \%$ Triton X-100 (15 min, RT). Cells were blocked in $1 \%$ bovine serum albumin (BSA) in PBS and stained with anti-Spa-1 antibodies $(2.5 \mu \mathrm{g} / \mathrm{ml} ; 2 \mathrm{~h}$; $1 \%$ BSA), followed by incubation with Cy3-conjugated antimouse IgG (Jackson ImmunoResearch Laboratories, Inc., West Grove, PA). After mounting in Vectashield containing 4',6'-diamidino-2-phenylindole (DAPI; Vector Laboratories, Burlingame, CA), cell images were obtained with a Leica TCS SP confocal microscope.

Lentiviral transduction of PLC1 cells and Nalm-6 cells. Viral packaging was performed by the CHLA vector core. Recombinant Spa-1 lentivirus was added to $2 \times 10^{5}$ PLC1 cells at a multiplicity of infection (MOI) of 50. After 6-h incubation, infected cells were plated on culture dishes containing mitotically inactivated mouse embryonic fibroblast feeder cells. For migration assays, PLC1 cells were infected with lentivirus supernatant including pCCL-c-MNDU3-PGK-EGFP or pCCL-c-MNDU3-Spa-1-PGK-EGFP at an MOI of 50 for $6 \mathrm{~h}$. Nalm-6 cells were transduced at a MOI of 10 overnight. After 5 days, GFP-positive cells were sorted using FACS (BD, Franklin Lakes, NJ).

Migration assays. For Nalm-6 cells, $2 \times 10^{5}$ cells in $100 \mu 1$ were placed in the upper compartment of Transwell inserts (6.5 mm diameter, $8 \mu \mathrm{m}$ pore size) (Coaster, Cambridge, MA). The lower compartment contained $600 \mu 1$ culture medium with or without SDF-1 $\alpha$ (10 ng/ml). For PLC1 cells, $2 \times 10^{5}$ cells in $100 \mu \mathrm{l}$ were placed in the upper compartment of Transwell inserts ( $6.5 \mathrm{~mm}$ diameter, $5 \mu \mathrm{m}$ pore size). The lower compartment contained $600 \mu 1$ culture medium with or without SDF- $1 \alpha$ $(100 \mathrm{ng} / \mathrm{ml})$. Cells were allowed to migrate for $1.5 \mathrm{~h}$ at $37^{\circ} \mathrm{C}$. The cells migrated into the lower compartment were collected, stained with Trypan blue, and counted using a hemocytometer. Each migration assay was performed in triplicate.

\section{Results}

We transfected COS-1 cells with Bcr/Abl and with Spa-1 to investigate whether we could detect an interaction between these two proteins. As shown in Fig. 1A, when we immunoprecipitated Bcr/Abl P190 or P210 using Abl antibodies from lysates in which they were co-transfected with Spa-1, Spa-1 was co-precipitated. Conversely, when Spa-1 was precipitated from such lysates, both the $\mathrm{Bcr} / \mathrm{Abl} \mathrm{P} 210$ protein and the shorter P190 protein were detected in complex with it (Fig. 1B).

$\mathrm{Bcr} / \mathrm{Abl}$ consists of a Bcr and an Abl segment. We have previously shown that the Bcr GAP domain forms a complex 

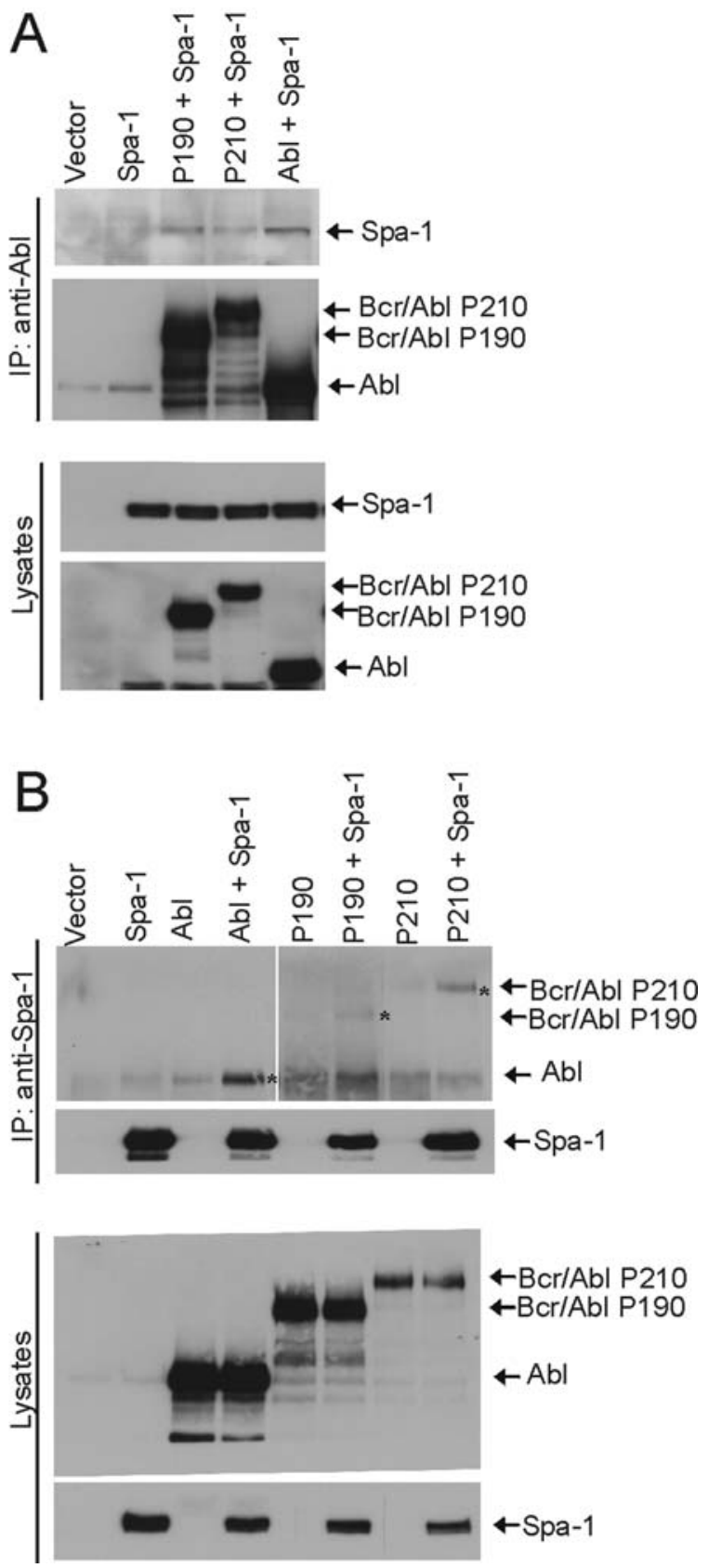

Figure 1. Bcr/Abl P190, P210 and normal c-Abl co-immunoprecipitate with Spa-1. COS-1 cells were transfected with the DNA constructs indicated above the lanes. The locations of the proteins detected in the Western blots with antiSpa-1 antibodies or anti-Abl antibodies are indicated with arrows to the right. (A), Immunoprecipitation with anti-Abl antibodies. (B), Immunoprecipitation with anti-Spa-1 antibodies. Each asterisk indicates Bcr/Abl P210, Bcr/Abl P190, or Abl.

with Spa-1 (Yi et al, unpublished data). The Bcr/Abl proteins lack the Bcr GAP domain, but Bcr and Bcr/Abl proteins can form a stable complex that is mediated through the $\alpha$-helix of the Bcr N-terminal oligomerization domain. Therefore, the interaction of Bcr/Abl with Spa-1 could possibly be mediated by a trimolecular complex consisting of Bcr/Abl, endogenous Bcr, and Spa-1.

To investigate if the Abl part of Bcr/Abl could also interact with Spa-1, we co-transfected normal c-Abl with Spa-1 and performed an immunoprecipitation with Abl antibodies. As shown in Fig. 1A, the two proteins formed a complex and Spa-1 immunoprecipitates also contained Abl (Fig. 1B).

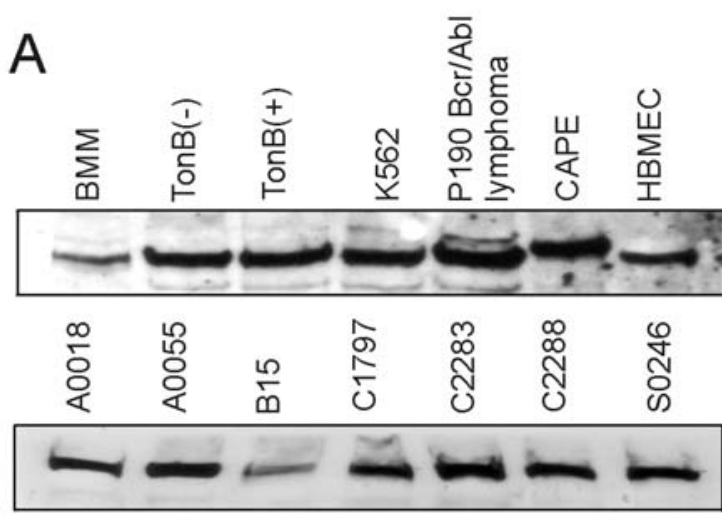

IB: anti-Spa-1

B
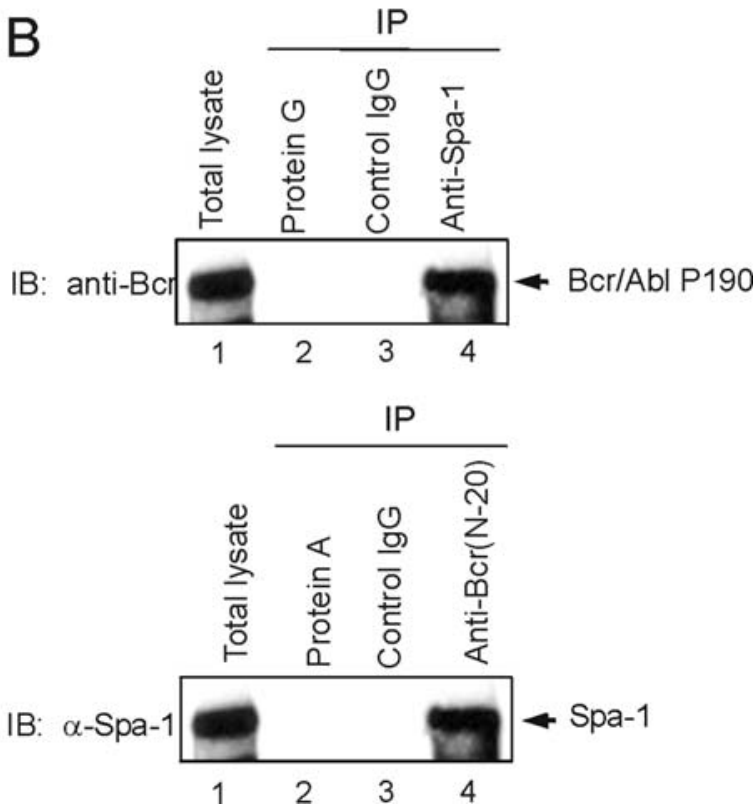

Figure 2. Spa-1 forms a complex with Bcr/Abl P190 in primary leukemia/ lymphoma cells. (A), Expression of Spa-1 protein in leukemia cell lines and primary samples. Total cellular lysates were blotted with anti-Spa-1 antibodies. Samples include BMM, murine bone marrow derived macrophages; TonB(-) murine lymphoid BaF3 cells not induced to express Bcr/Abl P210; $\mathrm{TonB}(+) \mathrm{BaF} 3$ cells induced to express Bcr/Abl P210; K562, Ph-positive erythroleukemic cell line; Bcr/Abl P190 lymphoma, acute lymphoblastic leukemia/lymphoma cells from a transgenic Bcr/Abl mouse; CPAE, cow pulmonary endothelial cells; HBMEC, human brain microvascular endothelial cells; A0018, non-Ph-positive ALL; A0055, Ph-positive ALL; B15, Ph-positive ALL; C1797, CML blast crisis; C2283, CML; C2288, CML; S0240, CLL. (B), Lysates prepared from the lymphoma of a BCR/ABL P190 transgenic mouse were used for immunoprecipitation using the antibodies shown above lanes 2-4. Antibodies used for Western blotting are shown to the left. A sample of the total lysate was also included (lane 1).

Kometani et al (12) reported that expression of $\mathrm{Bcr} / \mathrm{Abl}$ down-regulates Spa-1 levels when Bcr/Abl P210 is introduced into Linc-kit ${ }^{+}$progenitor cells, suggesting that Spa-1 levels are very low in Bcr/Abl Ph-positive leukemias. To examine this, we performed Western blot analysis on lysates made from primary cells. As shown in Fig. 2A, Spa-1 was expressed in all primary leukemia cell lysates tested including samples from human patients with both $\mathrm{Ph}$-positive and negative leukemias. Also, there was no difference in the level of Spa-1 protein between lysates made from $\mathrm{BaF} 3$ cells induced or 
non-induced for Bcr/Abl P210 expression [Fig. 2A, TonB(+) and (-)]. We have previously generated a mouse model for acute lymphoblastic leukemia caused by Bcr/Abl P190 (17). These mice, which are transgenic for human BCR/ABL P190, consistently develop leukemia or lymphoma/leukemia. Lysates from such primary leukemic cells also expressed Spa-1 (Fig. 2A). Finally, although Kurachi et al (19) reported that Spa-1 is selectively expressed in lymphoid tissues, we also clearly detected Spa-1 protein in bone marrow-derived macrophages and in human and bovine endothelial cell lines (Fig. 2A).

To investigate whether Spa-1 and Bcr/Abl P190 form a complex in these primary cells, we immunoprecipitated Spa-1 from these lysates using Spa-1 antibodies. As shown in Fig. 2B, Bcr/Abl P190 clearly formed a complex with it and was coimmunoprecipitated (upper panel, lane 4) and conversely, $\mathrm{Bcr} / \mathrm{Abl}$ precipitates contained Spa-1 (lower panel, lane 4).

Since $\mathrm{Bcr} / \mathrm{Abl}$ is a deregulated tyrosine kinase, we performed immunocomplex kinase assays using transfection in COS- 1 cells and co-precipitation to investigate if $\mathrm{Bcr} / \mathrm{Abl}$ could phosphorylate Spa-1. Also, the N-terminal domain of Bcr encodes a serine/threonine kinase, which potentially could utilize Spa-1 as a substrate. However, we did not obtain any evidence that Spa-1 becomes phosphorylated by either Bcr/Abl or Bcr (results not shown).

We next wished to investigate where in the cell these proteins interact. The subcellular location of Bcr/Abl P190 in the $B C R / A B L$ transgenic lymphoblastic leukemia cells has not been determined. We standardly culture such cells on mitotically inactivated murine embryonic fibroblasts (15). When such lymphoblasts are plated on the stromal feeder layers, they attach to these cells and also migrate underneath them. The fibroblasts were clearly distinguishable from the lymphoblasts by their larger nucleus, the prominent presence of actin stress fibers and their different shape. As shown in Fig. 3A, immunostaining for the Bcr/Abl P190 protein using antibodies against Bcr or against Abl showed two different locations, depending on the cell. Rapidly dividing PLC1 lymphoblasts showed very little polarization or cell surface protrusions. In these cells, anti-Bcr N20 antibody immunostaining showed a concentration of signal at the cell periphery, some of which co-localized with cortical actin. Z-sections of one of these confirmed the concentration of signal for Bcr/ Abl P190 and actin at the edge of the cell (Fig. 3A, upper panel). Staining with an anti-Abl monoclonal antibody, 3F12, showed a similar result and confirmed the peripheral location of P190 in such cells (Fig. 3A, lower panel). There were also cells that were more loosely interconnected and showed signs of polarization. Some of these Bcr/Abl P190 expressing cells had a clear leading edge and a uropod (the trailing edge) and migrated rapidly (not shown). Immunostaining of these cells for F-actin and with an Abl antibody showed a more diffuse cytoplasmic staining for Bcr/Abl, but with a clear concentration of the oncoprotein in the uropod (Fig. 3A, lower panel, arrows).

The antibodies used for Spa-1 on Western blots are not sensitive enough to allow detection of endogenous Spa-1 in these lymphoblasts using immunocytochemistry. Therefore, we constructed a lentiviral vector expressing Spa-1 and used this to transduce Spa-1 into the Bcr/Abl P190 leukemic cells. Western blotting of lysates prepared from such cells showed
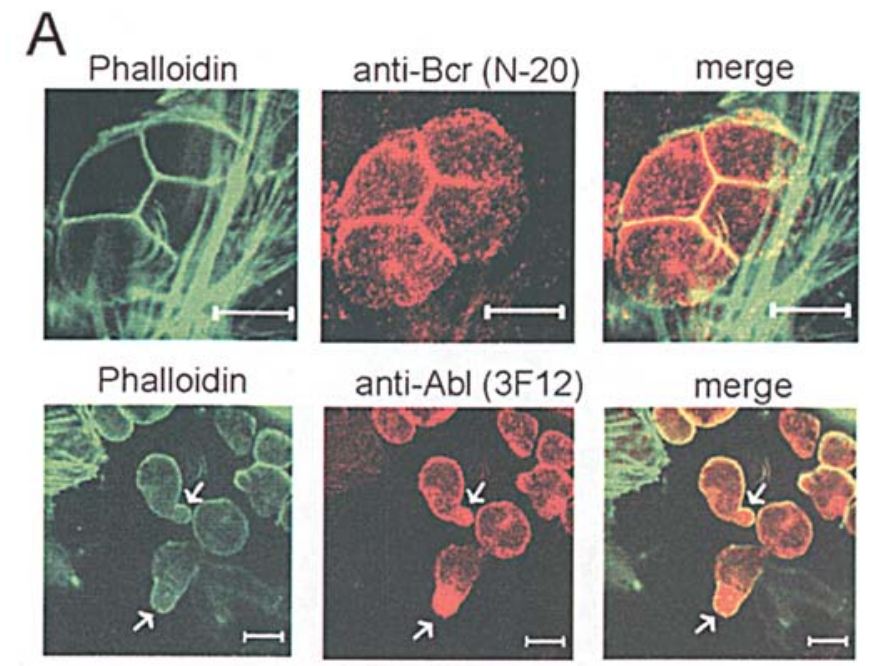

anti-Abl (3F12)
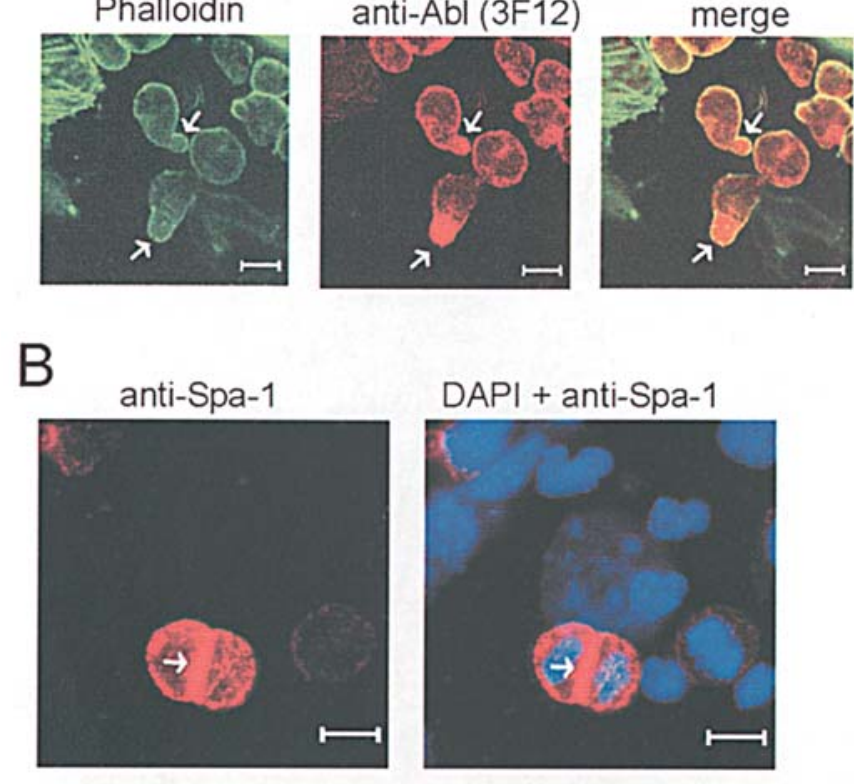

C
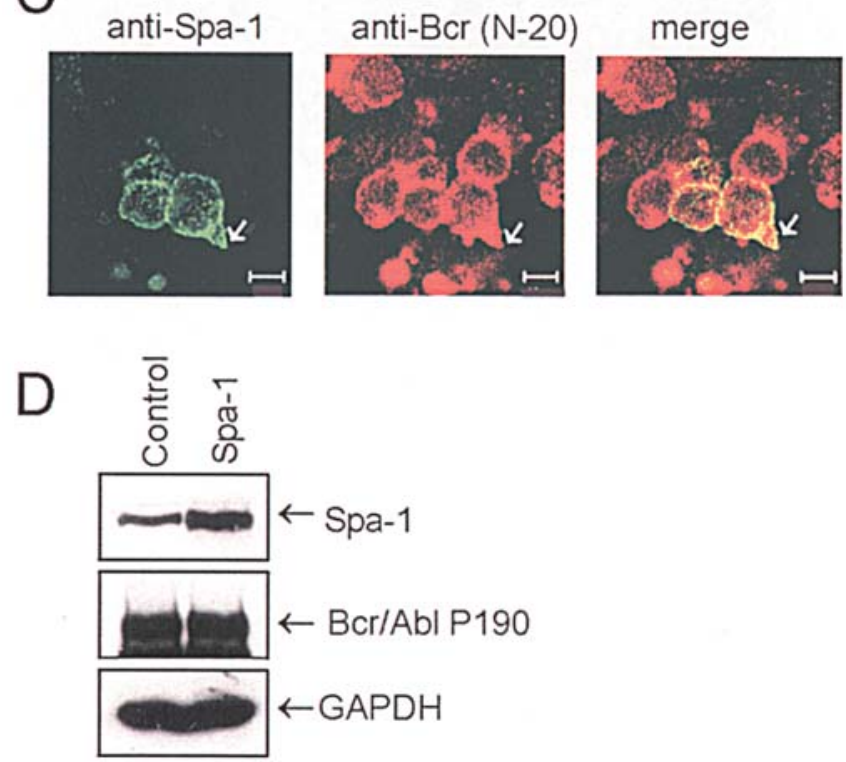

Figure 3. Localization of Bcr/Abl and Spa-1 in Bcr/Abl P190 lymphoblastic leukemia cells. All images are confocal. (A), PLC1 lymphoblastic leukemia cells were stained for F-actin (left panels) or for Bcr/Abl (middle panels). The right panels show the merged images. Top panel, Z-section of four lymphoblasts in between fibroblasts, showing the co-localization of Bcr/Abl signal with F-actin at the cell edges, including the interface between the cells. Bottom panel, polarized cells that develop a leading edge and a uropod (arrows). (B), Spa-1-transduced PLC1 cells were stained for Spa-1. Arrows point to the prominent signal of Spa-1 at the membrane of two newly divided cells. (C), Co-localization of Bcr/Abl P190 and Spa-1 in Spa-1-transduced PLC1 cells. Cells transduced with Spa-1 were immunostained for Spa-1 (left panel) or Bcr/Abl P190 (middle panel). The merged image is shown to the right. The bar represents $10 \mu \mathrm{m}$. (D), Western blot analysis of endogenous Spa-1 protein levels in PLC1 cells (control) or in the same cells transduced with a Spa-1 expressing lentivirus (Spa-1). 
A

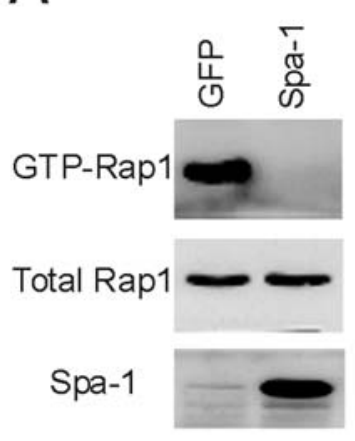

$B$

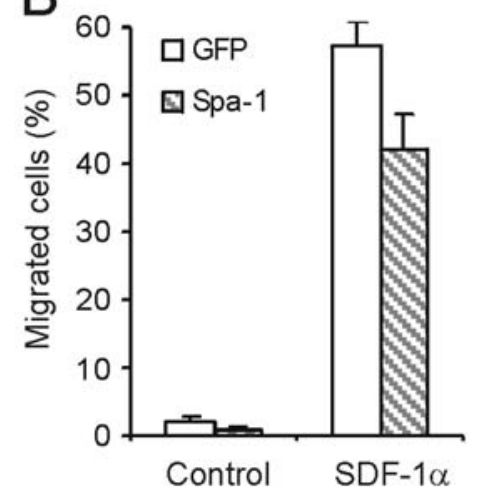

C

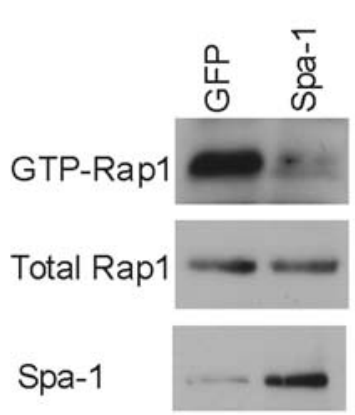

D

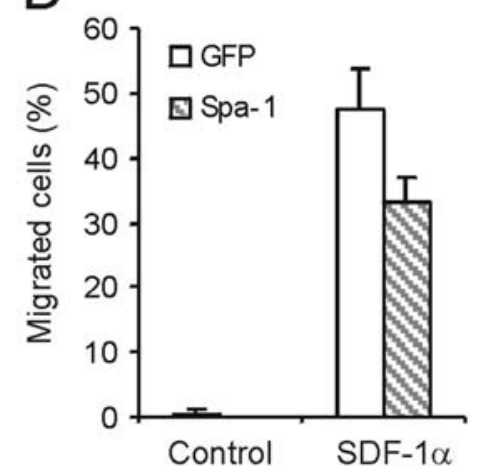

Figure 4. Spa-1 expression in B-lineage lymphoblastic leukemia cells negatively regulates migration. (A), Nalm-6 cells were transduced with lentiviral vectors expressing either EGFP (GFP) or Spa-1 and EGFP in a bicistronic vector (Spa-1) followed by flow sorting for GFP. Rap1 activation assays on endogenous Rap1 present in $1 \mathrm{mg}$ of lysate were performed as described in Materials and methods. (B), Cells $\left(2 \times 10^{5}\right.$ in $\left.100 \mu 1\right)$ were placed in the top chamber of a Transwell ( $8 \mu \mathrm{m}$ pore size) and assayed for their chemotaxis towards $10 \mathrm{ng} / \mathrm{ml} \mathrm{SDF}-1 \alpha$ in the bottom well for $1.5 \mathrm{~h}$. Control wells contained no SDF-1 $\alpha$ in the bottom well. The result shown is one of two independently performed experiments with similar results. Error bars indicate the standard deviation of mean. (C), PLC1 cells were transduced with lentiviral vectors expressing either EGFP (GFP) or Spa-1 and EGFP in a bicistronic vector (Spa-1) followed by flow sorting for GFP. Rap1 activation assays on endogenous Rap1 were performed as described in Materials and methods. (D), Cells $\left(2 \times 10^{5}\right.$ in $\left.100 \mu 1\right)$ were placed in the top chamber of a Transwell ( $5 \mu \mathrm{m}$ pore size) and assayed for their chemotaxis towards $100 \mathrm{ng} / \mathrm{ml} \mathrm{SDF}-1 \alpha$ in the bottom well for $1.5 \mathrm{~h}$. Control wells contained no SDF-1 $\alpha$ in the bottom well. The result shown is one of two independently performed experiments with similar results. Error bars indicate the standard deviation of mean of triplicate wells.

that there was an increase in Spa-1 levels of about 3- to 5-fold above endogenous Spa-1 (Fig. 3D, upper panel). In nonpolarized, rapidly dividing cells, the Spa- 1 signal concentrated mostly at the cell periphery (Fig. 3B) where it co-localized with F-actin (not shown). In polarized cells, Spa-1 protein was located at the trailing edge of the cell, at the cell periphery, and also in punctate structures inside the cell (Fig. 3C, left panel). Double staining of cells for Spa-1 and Bcr/Abl P190 showed that there was a large degree of overlap between the two signals (Fig. 3C, merge), in dividing cells at the cell periphery, and in polarized cells in part of the uropod.

Kometani et al (12) reported that hematopoietic progenitor cells lacking Spa-1 and transduced by Bcr/Abl P210 showed premature mobilization from the bone marrow. Also, Salgia et al (20) previously published that Bcr/Abl alters the chemo-

tactic response to SDF- $1 \alpha$. Since SDF- $1 \alpha$ is an important cytokine involved in migration and homing of lymphoblastic leukemia cells (21), we also measured the effect of Spa-1 expression on SDF- $1 \alpha$-directed chemotaxis of B-lineage lymphoblasts. Transduction of Spa- 1 into Nalm-6 cells confirmed that the lentiviral construct had significant Rap1 GAP activity (Fig. 4A). In comparison with GFP-transduced Nalm-6 cells, Spa-1 transduced cells had reduced chemotaxis towards SDF-1 $\alpha$ in a Transwell assay after $1.5 \mathrm{~h}$ (Fig. 4B). Expression of Spa-1 in PLC1 cells reduced GTP-Rap1 levels dramatically, regardless of the presence of Bcr/Abl P190 (Fig. 4C). Spa-1 expression also reduced the migration of the transgenic Bcr/Abl lymphoblasts towards SDF-1 $\alpha$ (Fig. 4D).

\section{Discussion}

In this study, we have shown that Bcr/Abl and Spa-1 form a protein complex that is present in leukemic cells from a Bcr/ Abl transgenic mouse model. In other experiments, we found that the normal Bcr protein forms a complex with Spa-1. This interaction is mediated by the GAP domain of Bcr, which is missing in $\mathrm{Bcr} / \mathrm{Abl}$ (Yi et al, unpublished data) and thus cannot be responsible for the Bcr/Abl-Spa-1 interaction. However, the normal Bcr protein forms a complex with the Bcr/Abl protein through the $\mathrm{N}$-terminal oligomerization domains present in $\mathrm{Bcr}$, and in this manner Spa-1 could be recruited into this complex. Surprisingly however, we found that the normal Abl protein can also bind to Spa-1, making it likely that the Bcr/ Abl-Spa-1 complex is mediated by the Abl moiety of Bcr/Abl.

We visualized endogenous Bcr/Abl P190 in lymphoblastic leukemia cells. These cells are very small with scant cytoplasm, hence it is difficult to distinguish subcellular features. Nevertheless, P190 was clearly visualized using both anti-Bcr and anti-Abl antibodies. A number of other studies have looked at the subcellular location of Bcr/Abl (22-24), some of which used cells transfected with Bcr/Abl, including NIH 3 T3 fibroblasts. The most informative study was by Skourides et al (23), who performed a detailed analysis on myeloid 32D cells transduced with a retrovirus expressing Bcr/Abl P210. Skourides et al (23) reported that in migrating cells, most of the Bcr/Abl protein was found in the trailing edge where it co-localizes with F-actin. In our primary cells, we also localized Bcr/Abl at the uropod of migrating cells. Skourides et al also found $\mathrm{Bcr} / \mathrm{Abl}$ at the cleavage furrow, a site containing polymerized actin. In addition, they reported that some of the Bcr/Abl was located in vesicle-like structures, which did not stain for endocytic or lysosomal markers. Interestingly, we also observed immunostaining of both Bcr/Abl and Spa-1 on intracellular punctuate structures and in the uropod.

Kometani et al (12) reported that Bcr/Abl P210 expression mediated by retroviral transduction reduces Spa-1 levels. Although it remains a possibility that this happens in the leukemic lymphoblasts of the Bcr/Abl transgenic mice, we could not find evidence to support an effect of $\mathrm{Bcr} / \mathrm{Abl}$ on Spa-1 protein levels. We have previously shown that Bcr/Abl activates $\mathrm{C} 3 \mathrm{G}$, leading to increased GTP-Rap levels. In the leukemic cells, it is therefore difficult to distinguish the roles of activation of $\mathrm{C} 3 \mathrm{G}$ from other possible effects such as degradation of Spa-1 on the overall GTP-Rap1 levels. Because Spa-1 co-localized with $\mathrm{Bcr} / \mathrm{Abl}$, it is also possible that $\mathrm{Bcr} / \mathrm{Abl}$ 
interferes with Spa-1 activity by mislocalizing it to a subcellular location where it aberrantly deactivates GTP-Rap1. The consequences of the Bcr/Abl Spa-1 interaction are currently under investigation.

Finally, our studies support the concept that Spa-1 is an important regulator of $\mathrm{Bcr} / \mathrm{Abl}$ leukemic cell movement, since its expression in the lymphoblastic leukemia cells decreased their chemotaxis. These results are in concordance with Kometani et al (12) who found that progenitor cells lacking Spa-1 and expressing Bcr/Abl prematurely exit the bone marrow and are associated with extramedullary hematopoiesis. This indicates that the Rap1 signal transduction pathway should be considered an important factor in and a possible target for drug development against $\mathrm{Ph}$-positive leukemias.

\section{Acknowledgements}

This work was supported by PHS grants CA090321 (N.H.), HL071945 and HL060231 (J.G.). We thank Hans Bos (Department of Physiological Chemistry and Centre of Biomedical Genetics, Utrecht, The Netherlands) and Michiyuki Matsuda (Department of Signal Transduction, Research Institute for Microbial Diseases, Osaka University, Japan) for the GST-RalGDS and Rap1 plasmids. Suparna Mishra is acknowledged for the PLC1 cells, Ravi Salgia (Department of Medicine, University of Chicago, Chicago, IL) for the generous gift of the 3F12 antibodies, and Ralph Arlinghaus (Department of Molecular Pathology, The University of Texas M.D. Anderson Cancer Center, Houston, TX) for the SDS-sample buffer lysates of the human patient samples. We thank the Vector Core and the Image Core of the CHLA for assistance with virus packaging and imaging.

\section{References}

1. Heisterkamp N and Groffen J: BCR/ABL gene structure and BCR function. In: Chronic Myeloid Leukemia: Biology and Treatment. Carella AM, Daley GQ, Eaves CJ, Goldman JM and Hehlman R (eds.) Informa Health Care, pp3-17, 2001.

2. Goldman JM and Melo JV: Chronic myeloid leukemia-advances in biology and new approaches to treatment. N Engl J Med 349: 1451-1464, 2003.

3. Druker BJ, Sawyers CL, Kantarjian H, Resta DJ, Reese SF, Ford JM, Capdeville R and Talpaz M: Activity of a specific inhibitor of the BCR-ABL tyrosine kinase in the blast crisis of chronic myeloid leukemia and acute lymphoblastic leukemia with the Philadelphia chromosome. N Engl J Med 344: 1038-1042, 2001.

4. Ottmann OG, Druker BJ, Sawyers CL, Goldman JM, Reiffers J, Silver RT, Tura S, Fischer T, Deininger MW, Schiffer CA, Baccarani M, Gratwohl A, Hochhaus A, Hoelzer D, FernandesReese S, Gathmann I, Capdeville R and O'Brien SG: A phase 2 study of imatinib in patients with relapsed or refractory Philadelphia chromosome-positive acute lymphoid leukemias. Blood 100: 1965-1971, 2002.

5. Cho YJ, Hemmeryckx B, Groffen J and Heisterkamp N: Interaction of Bcr/Abl with $\mathrm{C} 3 \mathrm{G}$, an exchange factor for the small GTPase Rap1, through the adapter protein Crkl. Biochem Biophys Res Commun 333: 1276-1283, 2005.

6. Mizuchi D, Kurosu T, Kida A, Jin ZH, Jin A, Arai A and Miura O: BCR/ABL activates Rap1 and B-Raf to stimulate the MEK/Erk signaling pathway in hematopoietic cells. Biochem Biophys Res Commun 326: 645-651, 2005.
7. Jin A, Kurosu T, Tsuji K, Mizuchi D, Arai A, Fujita H, Hattori M, Minato $\mathrm{N}$ and Miura O: BCR/ABL and IL-3 activate Rap1 to stimulate the B-Raf/MEK/Erk and Akt signaling pathways and to regulate proliferation, apoptosis, and adhesion. Oncogene 25: 4332-4340, 2006.

8. Bos JL, De Bruyn K, Enserink J, Kuiperij B, Rangarajan S, Rehmann H, Riedl J, De Rooij J, van Mansfeld F and Zwartkruis F: The role of Rap1 in integrin-mediated cell adhesion. Biochem Soc Trans 31: 83-86, 2003.

9. Dupuy AJ, Morgan K, von Lintig FC, Shen H, Acar H, Hasz DE, Jenkins NA, Copeland NG, Boss GR and Largaespada DA: Activation of the Rap1 guanine nucleotide exchange gene, CalDAG-GEF I, in BXH-2 murine myeloid leukemia. J Biol Chem 276: 11804-11811, 2001.

10. Ishida D, Kometani K, Yang H, Kakugawa K, Masuda K, Iwai K, Suzuki M, Itohara S, Nakahata T, Hiai H, Kawamoto H, Hattori M and Minato N: Myeloproliferative stem cell disorders by deregulated Rap1 activation in SPA-1-deficient mice. Cancer Cell 4: 55-65, 2003.

11. Kometani K, Ishida D, Hattori M and Minato N: Rap1 and SPA-1 in hematologic malignancy. Trends Mol Med 10: 401-408, 2004.

12. Kometani K, Aoki M, Kawamata S, Shinozuka Y, Era T, Taniwaki M, Hattori M and Minato N: Role of SPA-1 in phenotypes of chronic myelogenous leukemia induced by BCR-ABLexpressing hematopoietic progenitors in a mouse model. Cancer Res 66: 9967-9976, 2006.

13. Wang SF, Aoki M, Nakashima Y, Shinozuka Y, Tanaka H, Taniwaki M, Hattori M and Minato N: Development of Notchdependent T-cell leukemia by deregulated Rap1 signaling. Blood 111: 2878-2886, 2008.

14. Ten Hoeve J, Kaartinen V, Fioretos T, Haataja L, Voncken JW, Heisterkamp N and Groffen J: Cellular interactions of CRKL, and SH2-SH3 adaptor protein. Cancer Res 54: 2563-2567, 1994.

15. Mishra S, Reichert A, Cunnick J, Senadheera D, Hemmeryckx B, Heisterkamp N and Groffen J: Protein kinase CKIIalpha interacts with the Bcr moiety of Bcr/Abl and mediates proliferation of Bcr/Abl-expressing cells. Oncogene 22: 8255-8262, 2003.

16. Heisterkamp N, Jenster G, ten Hoeve J, Zovich D, Pattengale PK and Groffen J: Acute leukaemia in bcr/abl transgenic mice. Nature 344: 251-253, 1990.

17. Voncken JW, Griffiths S, Greaves M, Pattengale PK, Heisterkamp N and Groffen J: Restricted oncogenicity of BCR/ ABL P190 in transgenic mice. Cancer Res 52: 4534-4539, 1992.

18. Carey KD and Stork PJ: Nonisotopic methods for detecting activation of small G proteins. Methods Enzymol 345: 383-397, 2002.

19. Kurachi H, Wada Y, Tsukamoto N, Maeda M, Kubota H, Hattori M, Iwai K and Minato N: Human SPA-1 gene product selectively expressed in lymphoid tissues is a specific GTPaseactivating protein for Rap 1 and Rap2. Segregate expression profiles from a rap1GAP gene product. J Biol Chem 272: 28081-28088, 1997.

20. Salgia R, Quackenbush E, Lin J, Souchkova N, Sattler M, Ewaniuk DS, Klucher KM, Daley GQ, Kraeft SK, Sackstein R, Alyea EP, von Andrian UH, Chen LB, Gutierrez-Ramos JC, Pendergast AM and Griffin JD: The BCR/ABL oncogene alters the chemotactic response to stromal-derived factor-1alpha. Blood 94: 4233-4246, 1999.

21. Bradstock KF, Makrynikola V, Bianchi A, Shen W, Hewson J and Gottlieb DJ: Effects of the chemokine stromal cell-derived factor- 1 on the migration and localization of precursor-B acute lymphoblastic leukemia cells within bone marrow stromal layers. Leukemia 14: 882-888, 2000.

22. Wetzler M, Talpaz M, van Etten RA, Hirsh-Ginsberg C, Beran M and Kurzrock R: Subcellular localization of Bcr, Abl, and BcrAbl proteins in normal and leukemic cells and correlation of expression with myeloid differentiation. J Clin Invest 92: 1925-1939, 1993.

23. Skourides PA, Perera SA and Ren R: Polarized distribution of Bcr-Abl in migrating myeloid cells and co-localization of Bcr$\mathrm{Abl}$ and its target proteins. Oncogene 18: 1165-1176, 1999.

24. Wertheim JA, Perera SA, Hammer DA, Ren R, Boettiger D and Pear WS: Localization of BCR-ABL to F-actin regulates cell adhesion but does not attenuate CML development. Blood 102: 2220-2228, 2003. 